\title{
PROYECTO DE TÍTULO \\ Planta MBT+AD 4Mw en Montenegro, Til-Til: La tecnología aplicada a la arquitectura como transformador del paisaje
}

\author{
Alumno: Eduardo Ruz / Profesor Guía: Humberto Eliash D.
}

\section{Introducción}

Una planta MBT+AD esconde tras su nombre una de las tecnologías más prometedoras a futuro sobre el control de la basura de las ciudades. Lo que se traduce como Planta de Tratamiento Mecánico-Biológico con Digestión Anaerobia es un sistema que convierte los residuos orgánicos, en energía y bienes productivos.

Problemática: Del consumo a la degradación del paisaje гuг al

Actualmente vivimos en una economía de consumo, palabra que según la RAE tiene un significado claro y paradójicamente, poco económico:

Consumir. (Del latín consumêre). $1 /$ tr. Destruir extinguir. U. t. c. prnl. 2/ tr. Utilizar comestibles $\mathrm{u}$ otros bienes para satisfacer necesidades 0 deseos. 3/ tr. Gastar energía o un producto energético.

Nosotros, los «consumidores», no vamos realmente al supermercado a adquirir nuevos bienes. Lo que hacemos realmente es destruirlos, quemarlos, «consumirlos» en una «hoguera» a partir de una necesidad impuesta por la acelerada obsolescencia de los productos que adquirimos. Casi todo lo que compramos será basura dentro de un tiempo, inevitablemente. La basura que producimos termina en lo que conocemos vulgarmente como "vertedero" aunque en Chile los vertederos son cada vez menos comunes. Es más apropiado hablar de "relleno sanitario», que si bien sigue siendo un depósito de basura, suele ser tratado con medidas de mitigación medioambiental.
El relleno sanitario más grande de Chile es Lomas Los Colorados, en Til-Til, propiedad de KDM S.A. Recibe aproximadamente el $60 \%$ de los residuos domiciliarios de la Región Metropolitana, casi 2 millones de ton/ año de basura. Se encuentra ubicado en la comuna de Til-Til, el lugar menos poblado de la región. Sin embargo, está vecino al pueblo de Montenegro, de casi 600 habitantes, que sufre diariamente las consecuencias de vivir próximo a una instalación sanitaria: Ruidos de maquinarias, olores molestos, y el estigma de ser un «pueblo basurero» abandonado en precarias condiciones para estar a $60 \mathrm{~km}$ de la capital del país.

Esto me llamó la atención cuando realicé el proyecto de título, porque Montenegro es el lugar que paga el precio por la basura de 3 millones de habitantes. Montenegro hace un esfuerzo heroico para soportar las dificultades del día a día, y no recibe ningún beneficio que lo compense. Por esto, un aspecto prioritario que el proyecto debía abordar era la transformación de un paisaje adverso para sus pobladores en uno que reportara beneficios y proyectara una imagen diferente, innovadora y que pusiera a Montenegro en el mapa de forma positiva.

\section{El Proyecto: Regenerar el entorno}

Una planta MBT+AD era una solución adecuada para la recuperación de un entorno tan maltratado. Podría aprovechar la basura para producir biogás y electricidad. Con esto, se podría crear una red de bajo costo para la comuna y gratuita para Montenegro, menos contaminante que su símil de petróleo, afecto a las oscilaciones del precio del crudo. También el subproducto del proceso del biogás, el compost orgánico, podría ser un recurso abundante en una comuna donde el suelo se ve cada vez más afectado por la desertificación.

Sin embargo, una planta MBT+AD

convencional no basta, ya que el paisaje es un factor predominante, y aquí es donde entra el diseño arquitectónico en términos formales y espaciales. Las plantas MBT+AD se componen de enormes volúmenes que irrumpen en el paisaje de forma poco sutil, y por esto, se esconden de la vista del público. En este caso, el desafío consistía en hacer lo contrario, mostrar la planta y su impacto paisajístico para dar una nueva imagen al lugar.

La planta se ubicó en un terreno vecino al lugar donde se emplaza el relleno sanitario. El proyecto consiste principalmente en un enorme manto metálico ondulado que al romperse genera la espacialidad interior de la planta, albergando la maquinaria y el programa productivo. La idea de este manto provino de la necesidad de hacer converger en una solución unitaria elementos que se encontraban subordinados a formas específicas, con otros más flexibles y adaptables al paisaje. La cubierta integra grúas que ingresan la basura a la planta, su estructura sostiene las circulaciones interiores, el revestimiento permite canalizar aguas, controlar la luz y contener gases molestos. Exteriormente, la planta se inserta en el paisaje sinuoso de forma respetuosa y neutral, reconociendo también su vocación tecnológica.

Hay también una intención de revitalizar suelo degenerado por la desertificación aprovechando los productos orgánicos que recicla la planta; todo esto mediante un parque de dos hectáreas. La «maleza» es clave para mantener vivo el suelo, con especies vegetales que demandan poca agua. Combinado con 

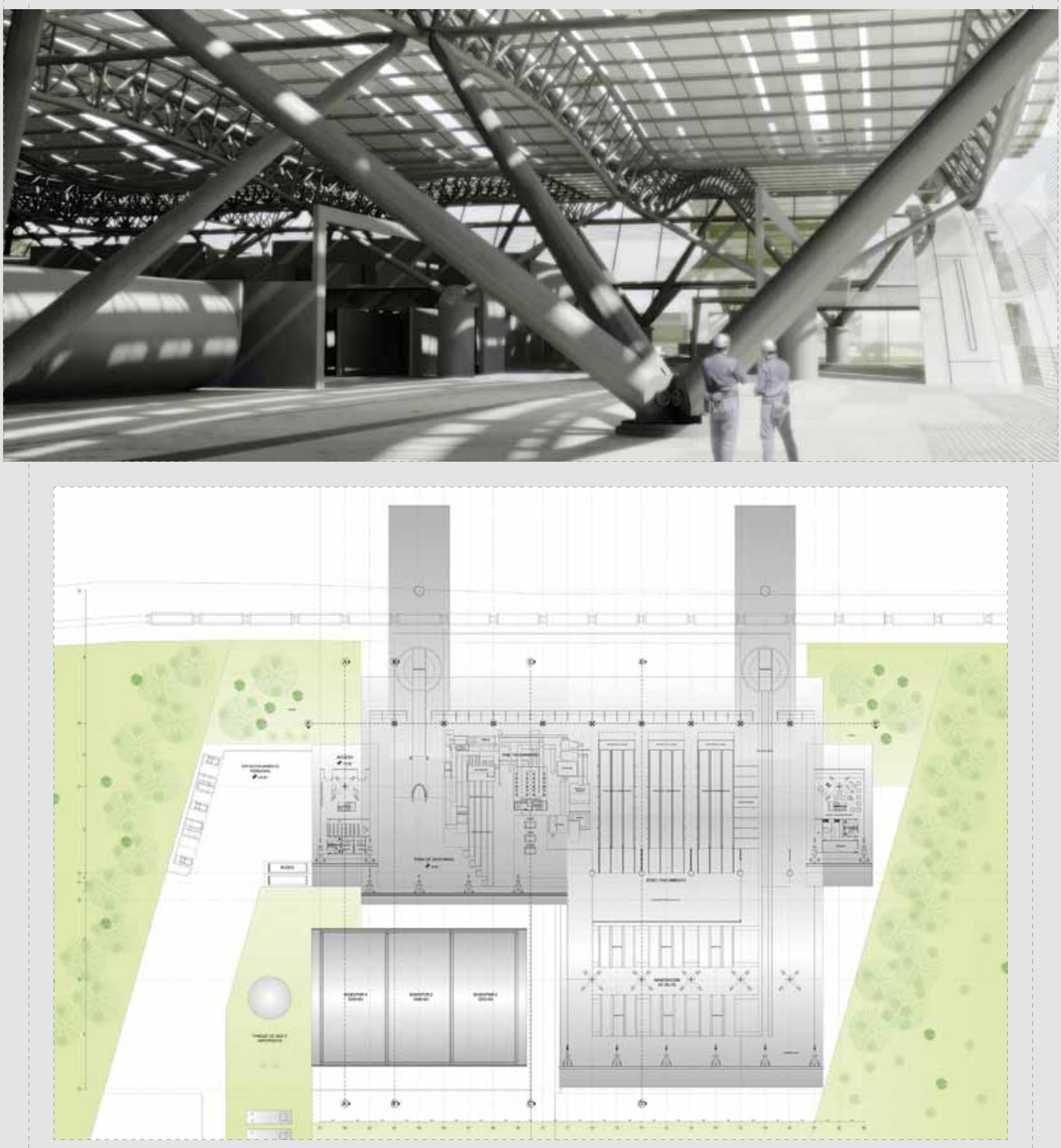

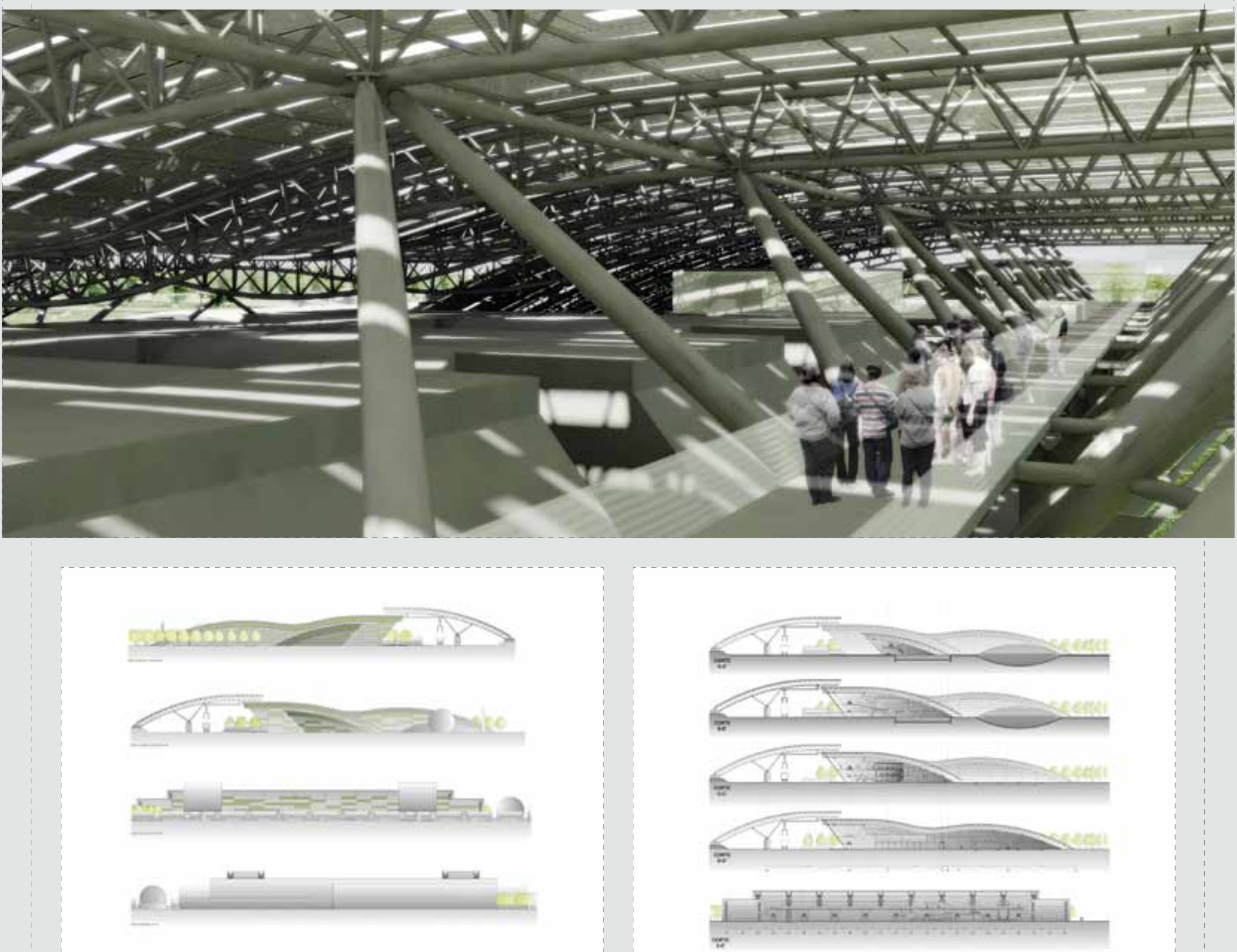

especies arbóreas resistentes a climas áridos, puede hacerse frente al agreste clima del lugar, que ha ido poco a poco extinguiendo las actividades agrícolas de la comuna de Til-Til.

El tema del paisaje también se aborda en el proyecto desde un enfoque a escala país. Al obtener una fuente de energía limpia, renovable y localizada se contribuye en mayor o menor medida de descentralizar el consumo energético. Es conocido, por ejemplo, el problema que representan las represas del proyecto HidroAysén, que pretende transportar grandes cantidades de energía al centro y norte del país, aunque ello represente pérdidas energéticas y ecológicas. Además, si se impulsa el uso de los recursos de cada región para autoabastecerse, sería posible ayudar además al país a no depender tanto de recursos energéticos externos como el petróleo, una fuente no renovable de energía.

\section{Conclusión}

Reconocer al paisaje como parte del proyecto es algo que siempre ha resultado clave en el trabajo de los arquitectos, y eso hoy toma una importancia mayor debido a nuevas soluciones que se están presentando para hacer frente a problemas como la contaminación ambiental y la escasez de energía. Como profesionales debemos tomar parte de esta corriente, ya que muchas otras disciplinas nos llevan bastante ventaja al respecto siendo que es en nuestro ámbito donde se definen las relaciones entre las personas y los lugares que habitan. 

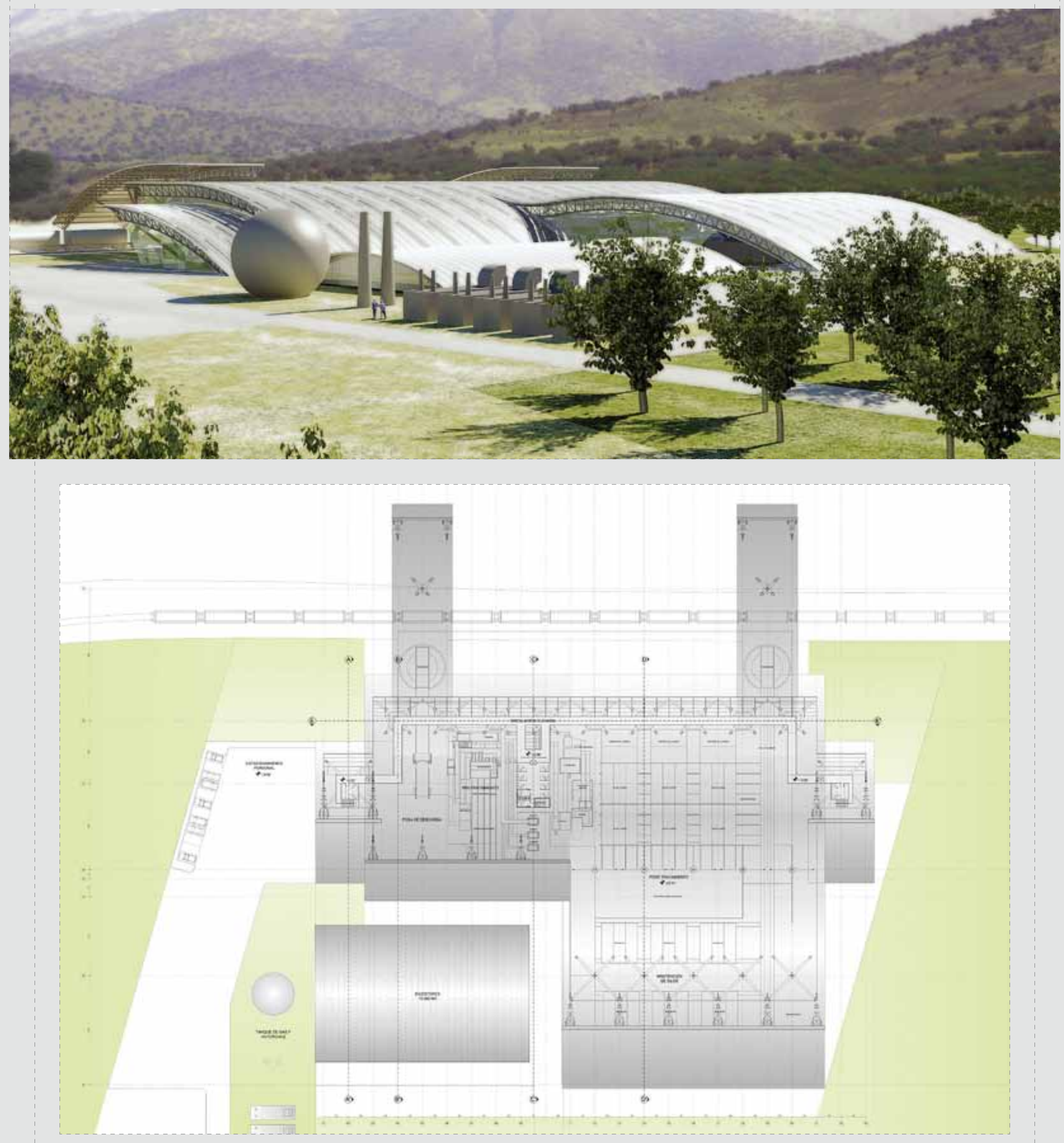